\title{
As grandes ausentes das inovações em Ciência e Tecnologia*
}

\begin{abstract}
Maria Margaret Lopes ${ }^{* *}$
As análises de gênero têm sido as grandes ausentes dos estudos dos processos de Inovação em Ciência e Tecnologia no Brasil. Isto não quer dizer que não existam estudos discutindo a participação de mulheres nas atividades tecnológicas, de pesquisa e ensino superior no país. Pelo contrário, desde meados dos anos de 1970, Carmem Barroso já inaugurava a nossa versão do "Why so few?". Mas é na década de 1980 que esses estudos começam a ganhar maior visibilidade no país, com a institucionalização dos núcleos de estudos sobre mulheres em diversas universidades brasileiras. E nesse aspecto não há dúvidas quanto ao papel pioneiro desempenhado por Fanny Tabak. Resultado de anos de trabalhos anteriores, Fanny Tabak foi fundadora, já no início dos anos de 1980, do primeiro desses núcleos - Núcleo de Estudos da Mulher - organizado na Pontifícia Universidade católica (PUC) do Rio de Janeiro. Desde então, seus trabalhos, ampliados agora no Laboratório de Pandora, têm sido referenciais para a área ainda emergente.

Considerando que "o país não pode se dar ao luxo de prescindir da incorporação de milhares de mulheres que venham a contribuir com seu talento e sua inteligência para fazer avançar a Ciência e a Tecnologia no Brasil" (p.13), a autora nos possibilita acompanhar diversas de suas pesquisas, nas quais tem avançado
\end{abstract}

\footnotetext{
" TABAK, Fanny. O Laboratório de Pandora. Rio de Janeiro, Garamond, 2002. Recebida para publicação em setembro de 2002.

** Professora livre-docente no Instituto de Geociências e coordenadora do Núcleo de Estudos de Gênero - Pagu, ambos da Unicamp.
} 
As grandes ausentes das inovações

análises de indicadores da produção científica sobre a presença $e$ o desempenho das mulheres nas ciências no Brasil nas décadas de 1970, 1980 e 1990. Inserindo o país no contexto internacional, em especial na América Latina, a autora enfatiza o incentivo decisivo de diferentes organizações internacionais e da UNESCO nas áreas de Ciência e Tecnologia - C\&T -, particularmente no que se refere à inserção da temática da participação feminina nas grandes conferências internacionais que marcaram a última década do século XX. Mais do que numa revisão bibliográfica, publiciza um conjunto de organizações, iniciativas, congressos, reuniões $e$ documentos internacionais da última década, de certa maneira ainda pouco conhecidos para além dos pesquisadores da área específica.

Apoiados em entrevistas e tabelas, dois capítulos do livro discutem em detalhes os resultados de um conjunto de pesquisas empreendidas pela autora em diversos universos de investigação, que abrangem a contribuição do CNPq e o papel da Universidade no contexto da política científica brasileira em relação à participação das mulheres. Em especial a UFRJ e a PUC do Rio e Janeiro são consideradas em termos da participação das mulheres nas diferentes carreiras científicas, desde os cursos de graduação, atividade docente, titulação, regime de trabalho, teses $e$ dissertações defendidas.

Entre seus outros universos de análise estão alunas de segundo grau de escolas públicas e privadas do Rio de Janeiro, encontros de mulheres cientistas e a Academia Brasileira de Ciências, cuja trajetória mais tardia não diferiu nem um pouco das práticas de exclusão das mulheres, características de outras academias como a francesa, famosa pela exemplaridade do caso de Marya Sklodowska - Mme. Curie. Da Academia brasileira, as mulheres permaneceram ausentes de 1916 a 1951 (por 35 anos) e, até o ano de 1995, correspondiam a 5,5\% (11 mulheres) do total dos 200 integrantes titulares.

No último capítulo, Fanny Tabak comenta algumas perspectivas atuais sobre as necessidades prementes de 
"mudanças substanciais" na educação científica e tecnológica no país. A educação diferenciada no ensino de ciências, desde o ensino fundamental, continua marcando decisivamente meninas e meninos. Apesar dos avanços das práticas e políticas em C\&T no Brasil, das "profundas transformações" do status jurídico das mulheres, das conquistas sociais lideradas pelos movimentos feministas, as carreiras científicas e tecnológicas continuam não sendo opções prioritárias para as mulheres. Este trabalho não se limita à análise dos indicadores tradicionais de participação das mulheres em C\&T. Apoiada em bibliografia internacional, a autora se aproxima dos procedimentos que têm norteado as práticas do atual Ministério de Ciência e Tecnologia que tentam, reajustando os indicadores tradicionais às particularidades do caso brasileiro, permitir análises comparativas internacionais.

Dos anos de 1980 para cá, fundamentos da tradição mertoniana em sociologia da ciência, que sustentam teoricamente tais indicadores, estão sofrendo profundas revisões pelas críticas construídas no contexto das diversas disciplinas que integram os chamados estudos sociais da ciência e tecnologia. Léa Velho, em recente artigo sobre o tema pergunta:

Como ficam, então, os indicadores científicos se a base teórica que lhes dava sustentação está prestes a desmoronar (...) particularmente em países cientificamente periféricos, em que pouco se sabe sobre a natureza, o caráter, o funcionamento $e$ a organização do sistema nacional de inovação?

1 VelHO, Lea M. S. Estratégias para um sistema de indicadores: C\&T no Brasil. Parcerias Estratégicas (13), Ministério da Ciência e Tecnologia, dezembro de 2001, pp.109-121. 
As grandes ausentes das inovações

O Laboratório de Pandora é um convite à reflexão sobre a necessidade de sofisticação e de incorporação nas análises de política científica, de indicadores que, também a partir de perspectivas de gênero, questionem os quadros teóricosconceituais em que se apóiam os indicadores tradicionais de C\&T no país. 